\title{
Neutral Diboron Analogues of Archetypal Aromatic Species by Spontaneous Cycloaddition
}

\author{
Merle Arrowsmith, Julian Böhnke, Holger Braunschweig, * Mehmet Ali Celik, Christina Claes, William C. Ewing, \\ Ivo Krummenacher, Katharina Lubitz, Christoph Schneider
}

\begin{abstract}
Among the numerous routes organic chemists have developed to synthesize benzene derivatives and heteroaromatic compounds, transition metal-catalyzed cycloaddition reactions are the most elegant. In contrast, cycloaddition reactions of heavier alkene and alkyne analogues, though limited in scope, proceed uncatalyzed. In this work we present the first spontaneous cycloaddition reactions of lighter alkene and alkyne analogues. Selective addition of unactivated alkynes to boron-boron multiple bonds under ambient conditions yielded diborocarbon equivalents of simple aromatic hydrocarbons, including the first neutral $6 \pi$-aromatic

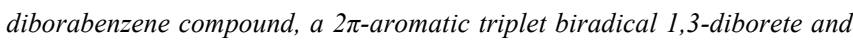

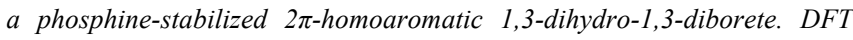
calculations suggest that all three compounds are aromatic and show frontier molecular orbitals matching those of the related aromatic hydrocarbons, $\mathrm{C}_{6} \mathrm{H}_{6}$ and $\mathrm{C}_{4} \mathrm{H}_{4}{ }^{2+}$, and homoaromatic $\mathrm{C}_{4} \mathrm{H}_{5}{ }^{+}$.
\end{abstract}

The selective construction of Hückel-aromatic carbo- and heterocycles has mobilized ${ }^{[1]}$ countless researchers throughout the last two centuries. Today aromatic compounds account for nearly one third of all small organic molecules produced on an industrial $\mathrm{scale}^{[2]}$ and are key components in such diverse areas as drug development, ${ }^{[3]}$ chemical and biological molecular recognition, ${ }^{[4]}$ energetic materials ${ }^{[5]}$ and fuel cells ${ }^{[6]}$ among others. Since the discovery of nickel-catalyzed acetylene cyclotrimerization in the $40 \mathrm{~s},{ }^{[7]}$ late transition metal-catalyzed alkyne $[2+2+2]$ cycloaddition reactions have been widely used as the most elegant synthetic route to access benzene derivatives (Fig. 1) ${ }^{[8]}$ Due to large enthalpic and entropic barriers, however, the vast majority of alkyne cycloaddition reactions either require a catalyst or forcing thermal conditions. ${ }^{[9]}$

In contrast alkene and alkyne analogues of the heavier p-block elements tend to undergo facile uncatalyzed cycloaddition reactions with unactivated alkynes. Disilenes, digermenes and distannenes, for example, undergo formal [2+2] cycloaddition with polar alkynes to form the corresponding 1,2-ditetrel-3-cyclobutenes, I (Fig. 1). ${ }^{[10]}$ In some cases of bridged distannenes, this reaction was shown to be reversible. ${ }^{[1]]}$ Recently the isolation of the first heavier group 14 alkyne analogues has also enabled the synthesis of the first $6 \pi$-aromatic $1,2-$ disilabenzene derivatives, IIa and IIb, and $4 \pi$-antiaromatic 1,2digermacyclobutadiene, III, by alkyne cycloaddition (Fig. 1). ${ }^{[12]}$ As regards heavier group 13 alkene analogues, Tokitoh and co-workers described the addition of alkynes to a dialumene-benzene adduct leading to the formation of 1,2-dialuminacyclobut-3-enes, IV (Fig.

$\left.{ }^{*}\right] \quad$ Dr. M. Arrowsmith, J. Böhnke, Prof. Dr. H. Braunschweig, Dr. M. A Celik, C. Claes, Dr. W. C. Ewing, Dr. I. Krummenacher, Dr. K. Lubitz, C. Schneider Institut für Anorganische Chemie Julius-Maximilians-Universität Würzburg Am Hubland, 97074 Wírzburg (Germany) E-mail: h.braunschweig@uni-wuerzburg.de

Supporting information for this article is available on the WWW under
1), ${ }^{[13]}$ while Power and co-workers synthesized 1,4-digallacyclohexa2,5-diene $\mathbf{V}$ by double cycloaddition of phenylacetylene to a digallene (Fig. 1). ${ }^{[14]}$

Transition metal catalyzed cyclotrimerization of alkynes

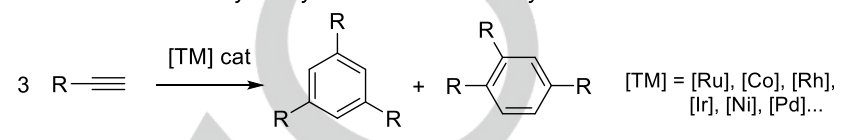

Uncatalyzed alkyne cycloaddition to heavier homodinuclear p-block multiple bonds

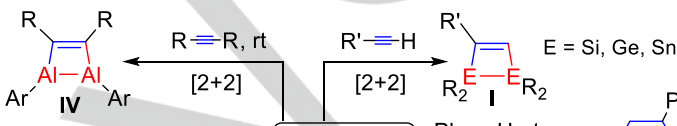$$
\mathrm{Ar}=2,6-\left[\mathrm{CH}\left(\mathrm{SiMe}_{3}\right)_{2}\right]_{2} \mathrm{C}_{6} \mathrm{H}_{3}
$$
$\mathrm{R}=\mathrm{Ph}, \mathrm{SiMe}_{3}$

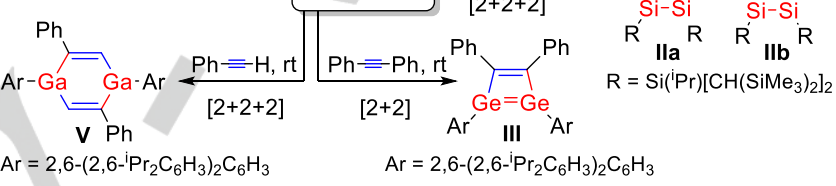

Figure 1. Alkyne cycloaddition to multiply bonded, homodinuclear p-block species.

Owing to the increasing popularity of boron-containing aromatics as therapeutic agents ${ }^{[15]}$ or luminescent hybrid organic molecules, ${ }^{[16]}$ controlled and efficient cycloaddition routes towards these compounds would be highly desirable. Thus far, however, even the synthesis of such a simple molecule as the benzene analogue, 1,2-dihydro-1,2azaborabenzene $\left[\mathrm{BNC}_{4} \mathrm{H}_{6}\right]$, necessitates a complex seven-step route, ${ }^{[17]}$ whereas the neutral borabenzene molecule $\left[\mathrm{BC}_{5} \mathrm{H}_{5}\right]$ has thus far eluded synthesis. Requisite for controlled cycloaddition, stable, neutral compounds containing B-B multiple bonds remained unknown until the report in 2007 by Robinson and co-workers of the first Nheterocyclic carbene (NHC)-stabilized diborene. ${ }^{[18]}$ Since then our group has synthesized the first compound with a B-B triple bond as well as a cyclic (alkyl)(amino)carbene (CAAC)-stabilized diboracumulene. ${ }^{[19]}$

Herein we now report the selective synthesis of a variety of novel $2 \pi$ - and $6 \pi$-aromatic borocarbon heterocycles by spontaneous cycloaddition of unactivated alkynes with diborenes and diboracumulenes, making these the first uncatalyzed cycloaddition reactions of lighter alkene and alkyne analogues.

Preliminary experiments revealed that NHC-stabilized diborenes display no reactivity towards acetylenes even under forcing or photolytic conditions. Therefore the phosphine-stabilized diborene VI ${ }^{[20]}$ was employed in the hope that the lability of the $\mathrm{PMe}_{3}$ ligands would enable cycloaddition. Under photolytic conditions in $\mathrm{Et}_{2} \mathrm{O}$, the phosphine-stabilized diborene VI underwent quantitative reaction within 4 hours at room temperature with one equivalent of 2-butyne, to yield a colorless solution (Fig. 2). Removal of the solvent and washing of the residue with pentane yielded a colorless solid presenting a broad ${ }^{11} \mathrm{~B}$ NMR singlet at $25.6 \mathrm{ppm}$, characteristic of a three-coordinate boron center, and a new broad ${ }^{31} \mathrm{P}$ NMR resonance at $23.1 \mathrm{ppm}$, both significantly downfield of the diborene NMR resonances at $\delta_{11 \mathrm{~B}} 16.7$ and $\delta_{31 \mathrm{P}}-24.4 \mathrm{ppm}$, respectively. ${ }^{[20]}$ 


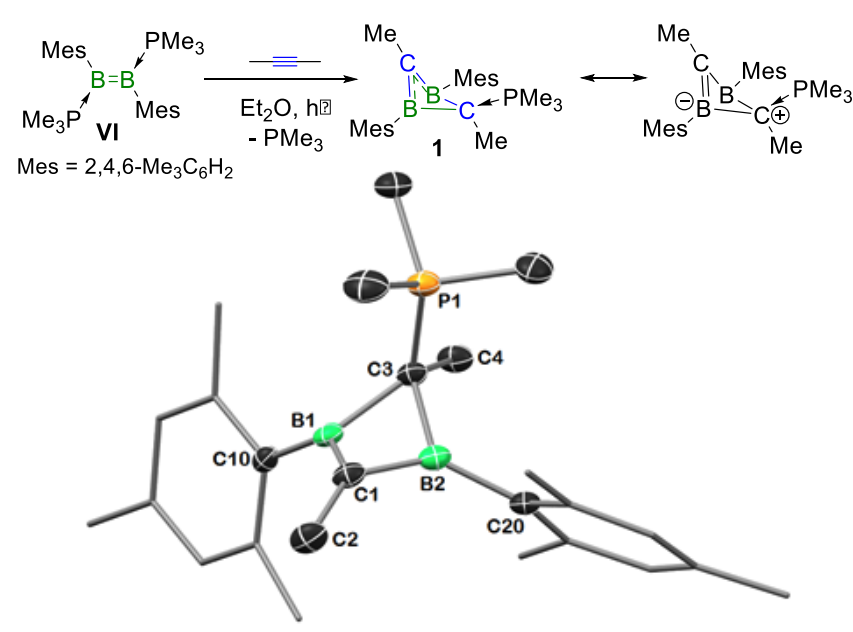

Figure 2. Reaction of 2-butyne with diborene VI. X-ray crystallographic structure of one of the molecules of 1 present in the asymmetric unit. Thermal ellipsoids are depicted at the $50 \%$ probability level. For clarity, hydrogen atoms and thermal ellipsoids of the mesityl carbon atoms are removed. Selected bond lengths $(\AA)$ and angles $\left({ }^{\circ}\right)$ : B1-C1 1.486(4), B2-C1 1.465(4), B1-C3 1.630(4), B2-C3 1.666(4), B1“B2 1.878(4), C3-P1 1.759(2), B1-C1-B2 79.0(2), B1-C3-B2 69.5(2), C1-B1-C3 99.7(2), C1-B2-C3 98.9(2).

Single-crystal X-ray analysis revealed an asymmetric unit comprised of two molecules of compound 1, a monophosphine-stabilized homoaromatic 1,3-dihydro-1,3-diborete in which phosphine coordination has shifted from boron to one of the carbon atoms of the central $\mathrm{BCBC}$ ring (Fig. 2). The latter presents a butterfly structure with carbon atoms located at the wing tip sites and a puckering angle of ca. $34.5^{\circ}$. Whereas the analogous reaction with a dialumene precursor yields the 1,2-dihydro-1,2-dialumete IV (Fig. 1) ${ }^{[13]}$ the 1,3isomer is obtained in this case. Although this reaction involves formal $\mathrm{C} \equiv \mathrm{C}$ and $\mathrm{B}=\mathrm{B}$ bond cleavage, previous synthetic and theoretical studies have shown that 1,2-dihydro-1,2-diboretes spontaneously rearrange to the thermodynamically more stable 1,3 -isomer. ${ }^{[21]}$ It is thus likely that diborene VI first undergoes the expected [2+2] cycloaddition to the kinetic 1,2-dihydro-1,2-diborete which immediately rearranges to the thermodynamic product, 1 . The short $\mathrm{B}-$ $\mathrm{C}$ bond lengths to $\mathrm{sp}^{2}$ hybridized $\mathrm{C} 1$ [1.486(4), 1.465(4) $\AA$ ] are indicative of a $2 \pi$-homoaromatic system delocalized over B1C1B2, whereas the B-C bonds to $\mathrm{sp}^{3}$ hybridized C3 [1.630(4), 1.666(4) $\AA$ ] are within the upper range of $\mathrm{B}-\mathrm{C}$ single bonds. Compound $\mathbf{1}$ is thus structurally similar to the allenyl-bridged 1,3-dihydro-1,3-diborete reported by Berndt and co-workers. ${ }^{[22]}$ The P1-C3 distance [1.759(2) $\AA]$ is typical of a $\mathrm{P} \rightarrow \mathrm{C}$ donor-acceptor bond; the $\mathrm{PMe}_{3}$ donor moiety thus stabilizes the build-up of positive charge on $\mathrm{C} 3$ (mesoionic resonance structure in Fig. 2).

Due to the enhanced $\pi$-acceptor properties of CAAC versus NHC ligands the CAAC-stabilized diboracumulene VII may be regarded as an intermediate bonding case between electron-precise diborenes $(\mathrm{B}=\mathrm{B})$ and diborynes $(\mathrm{B}=\mathrm{B}) .{ }^{[19]}$ It was thus of interest to compare its reactivity towards alkynes with that of VI. A violet solution of VII in benzene, left unstirred under an atmosphere of propyne, turned deep blue over the course of one day at room temperature (Fig. 3). NMR spectroscopic analysis of the reaction mixture showed no ${ }^{11} \mathrm{~B}$ NMR resonance and only very broad and weak ${ }^{1} \mathrm{H}$ NMR signals, suggesting the formation of a paramagnetic species. This was further confirmed by an EPR measurement of a frozen-solution sample of $\mathbf{2}$ in 2methyltetrahydrofuran which yielded a weak half-field signal and a four-line spectrum in the $g=2$ region attributable to the triplet state of biradical 2 (Fig. S3).
Slow evaporation of the solvent from the deep blue reaction mixture yielded blue crystals suitable for X-ray crystallography. This revealed the structure of compound $\mathbf{2}$, comprised of a central fourmembered $\mathrm{BCBC}$ ring, supported by two boron-coordinated CAAC ligands (Fig. 3). As in compound $\mathbf{1}$ the core ring adopts a butterfly structure, this time with boron atoms located at the wing-tip sites, a puckering angle of $40.2^{\circ}$, and two $\mathrm{sp}^{2}$ hybridized endocyclic carbon atoms. Bond lengths and angles within the $\mathrm{BCBC}$ ring are reminiscent of those in the known 1,3-dihydro-1,3-diborete species $\left[\left({ }^{\mathrm{i}} \operatorname{Pr}_{2} \mathrm{~N}\right) \mathrm{BCH}\right]_{2}$, suggesting a similar $2 \pi$-aromatic electronic configuration. ${ }^{[23]}$ As a result the two unpaired electrons must be localized on the CAAC ligands and not within the 1,3-diborete ring. The $\mathrm{B}-\mathrm{C}_{\mathrm{CAAC}}$ bond lengths $[1.498(2), 1.500(2) \AA]$ are significantly longer than in the boracumulene VII $[1.459(2), 1.458(2) \AA],{ }^{[19]}$ but still short for covalent single or pure $\sigma$-donor bonds, denoting some degree of $\pi$-backbonding from the cyclic system to the CAAC carbon atom. The preferential formation of a biradical [CAAC]-stabilized $2 \pi$-aromatic diborete instead of a neutral CAAC-stabilized $4 \pi$-antiaromatic 1,3diboracyclobutadiene may be explained by the higher stability of the aromatic system combined with the well-known ability of CAAC ligands to delocalize electron density and form [CAAC] ${ }^{\circ}$ radicals. ${ }^{[4]}$ Furthermore, while a butterfly conformation may seem counterintuitive for an aromatic ring, ab initio molecular orbital theory studies have shown that the puckered structure of $2 \pi$-aromatic 1,3 -diboretes is significantly more stable than a planar conformation. ${ }^{[25]}$ Unlike diborene VI, VII did not display any reactivity towards 2-butyne under these reaction conditions.

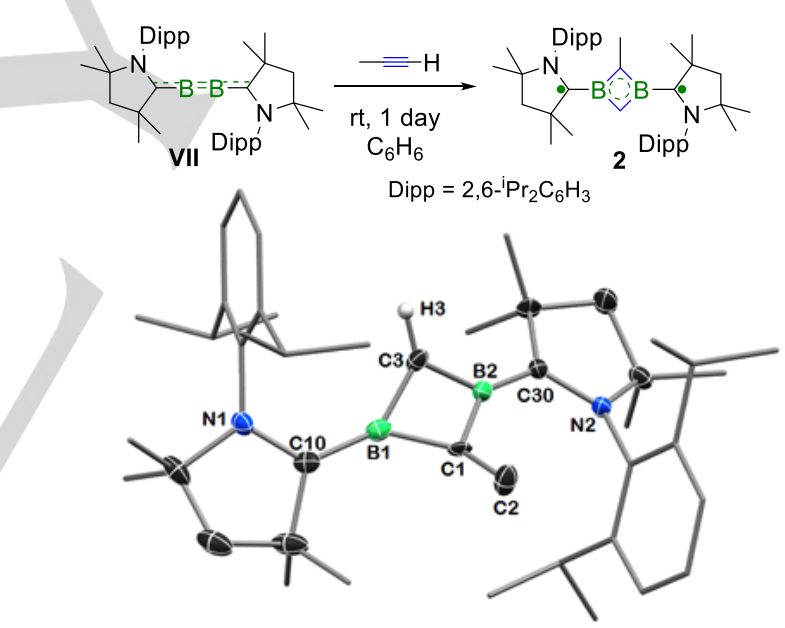

Figure 3. Synthesis of the triplet biradical 1,3-diborete 2 from the addition of propyne to VII. X-ray crystallographic structure of $\mathbf{2}$. Thermal ellipsoids are depicted at the $50 \%$ probability level. For clarity, hydrogen atoms and thermal ellipsoids of the mesityl carbon atoms are removed. Selected bond lengths $(\AA)$ and angles $\left({ }^{\circ}\right)$ : B1-C1 1.511(9), B2-C1 1.60(1), B1-C3 1.48(1), B2-C3 $1.57(1)$, C1 $\cdots C 3$ 1.81(2), B1-C10 1.498(3), B2-C30 1.499(3), B1-C1-B2 96.4(6), B1-C3-B2 99.2(6), C1-B1-C3 74.4(6), C1-B2-C3 69.6(5).

Although the analogous reaction with acetylene (Fig. 4) also yielded a deep blue solution, the resulting product, $\mathbf{3}$, proved to be diamagnetic and presented a single ${ }^{11} \mathrm{~B}$ NMR resonance of 24.8 ppm (Fig. 4). Examination of the ${ }^{1} \mathrm{H}$ NMR spectrum also provided a characteristic singlet at $7.31 \mathrm{ppm}$, integrating at $4 \mathrm{H}$ relative to the CAAC-derived resonances, and correlating with a ${ }^{13} \mathrm{C}$ resonance at $150.5 \mathrm{ppm}$, hinting at the formation of a six-membered $6 \pi$-aromatic $\mathrm{B}_{2} \mathrm{C}_{4}$ ring. This was later confirmed by an X-ray diffraction experiment of $\mathbf{3}$, which revealed the expected 1,4-diborabenzene ring supported by two boroncoordinated CAAC ligands (Fig. 4). Ab initio calculations have shown the 1,4-diborabenzene isomer to be significantly more stable than the other possible product of this reaction, the 1,2 -isomer. ${ }^{[26]}$ While 
dianionic aromatic diboratabenzenes have been known since the $1980 \mathrm{~s},{ }^{[27]}$ compound 3 is, to our knowledge, the first example of an isolated, neutral $6 \pi$-aromatic diborabenzene species.

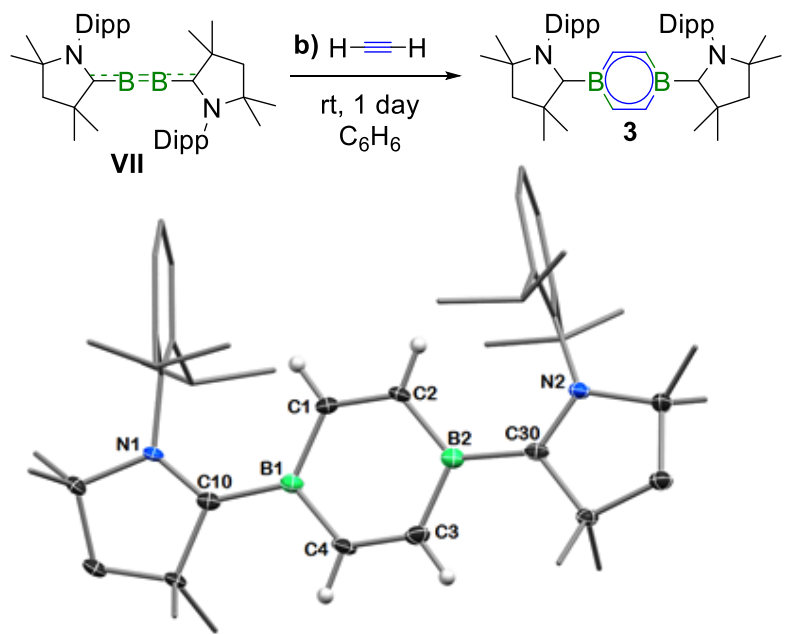

Figure 4. Synthesis of neutral 1,4-diborabenzene 3 from the addition of acetylene to VII. X-ray crystallographic structure of 3. Thermal ellipsoids are depicted at the $50 \%$ probability level. For clarity, hydrogen atoms and thermal ellipsoids of the mesityl carbon atoms are removed. Selected bond lengths $(\AA)$ and angles $\left({ }^{\circ}\right)$ : B1-C1 1.540(3), B1-C4 1.522(3), B2-C2 1.534(3), B2-C3 1.532(4), C1-C2 1.378(3), C3-C4 1.372(3), B1-C10 1.563(3), B2-C30 1.554(3), B1-C1-C2 122.1(2), C1-C2-B2 122.6(2), C2-B2-C3 114.7(2), B2C3-C4 122.7(2), C3-C4-B1 122.8(2), C4-B1-C1 115.1(2).

Unlike the $\mathrm{B}_{2} \mathrm{C}_{2}$ ring of $\mathbf{2}$, the $\mathrm{B}_{2} \mathrm{C}_{4}$ ring of compound $\mathbf{3}$ is perfectly planar, with angles close to the idealized $120^{\circ}$ of a benzene ring $\left[114.8(2)-122.8(2)^{\circ}\right]$. The mean planes of both CAAC ligand frameworks are quasi-coplanar with the 1,4-diborabenzene ring (dihedral angles ca. 7.0 and $7.9^{\circ}$ ). The $\mathrm{B}-\mathrm{C}$ bonds within the ring $[1.522(3)-1.540(3) \AA]$ are elongated compared to related Lewis basestabilized aromatic borabenzene compounds [ca. $1.49 \AA] .{ }^{[28]}$ The $\mathrm{C}-\mathrm{C}$ distances within the ring $[1.372(3), 1.378(3) \AA]$, although slightly shorter than in the related borabenzene adducts [ca. $1.40 \AA]$ ] ${ }^{[28]}$ are still significantly longer than the formal $\mathrm{C}=\mathrm{C}$ double bonds in the related 1,4-difluoro-2,3,5,6-tetramethyl-1,4-dibora-2,5-cyclohexadiene $\quad \mathrm{B}_{2} \mathrm{C}_{4}$ ring $[1.329(7) \AA],{ }^{[29]}$ suggesting significant electron delocalization throughout the 1,4-diborabenzene ring. For comparison the $\mathrm{B}-\mathrm{C}$ and $\mathrm{C}-\mathrm{C}$ distances of the parent 1,4-diborabenzene, $\left[\mathrm{B}_{2} \mathrm{C}_{4} \mathrm{H}_{4}\right]$, were calculated to be 1.452 and $1.450 \AA$, respectively. ${ }^{[26]}$ The bond length variations within the $\mathrm{B}_{2} \mathrm{C}_{4}$ ring in 3 likely arise from the $\pi$-acceptor properties of the supporting CAAC ligands. The elongated $\mathrm{B}-\mathrm{C}_{\mathrm{CAAC}}$ distances $[1.554(3), 1.563(3) \AA]$, however, suggest $\pi$-backbonding from the diborabenzene ring to the CAAC ligands is significantly weaker than in VII [B-C CAAC 1.459(2), 1.458(2) $\AA] .{ }^{[19]}$ The formation of the six-membered diborabenzene compound $\mathbf{3}$, when using acetylene rather than propyne, suggests a stepwise formation mechanism via a four-membered 1,2-diborete. The fact that the reaction with excess propyne does not proceed through to the diborabenzene product under these reaction conditions may be ascribed to the larger steric demands of propyne versus acetylene hindering a second insertion. Cyclic voltammetry of compound $\mathbf{3}$ in THF showed two reversible reduction waves $\left(\mathrm{vs} \mathrm{Fc} / \mathrm{Fc}^{+}\right.$) at -0.81 and $-2.48 \mathrm{~V}$, respectively (Fig. S2), hinting at the possibility of selective chemical reduction of this species.

In order to analyze the $\pi$-bonding in compounds $\mathbf{1 - 3}$, density functional theory calculations were performed on all three structures optimized at BP86/def2-SVP level, with $\mathbf{1}$ and $\mathbf{3}$ as singlet closed-shell and 2 as triplet biradical compounds. Structural parameters of the optimized structures were in good agreement with X-ray crystallographic data (Fig. 5, Fig. S6, S8 and S10). The HOMO of $\mathbf{1}$ corresponds to the delocalized $2 \pi$-homoaromatic system of the $1,3-$ dihydro-1,3-diborete ring and closely resembles that of the related $2 \pi$ homoaromatic $\mathrm{C}_{4} \mathrm{H}_{5}^{+}$cation (Fig. 5a). The two SOMOs of 2 clearly show the two unpaired electrons to be mainly localized on the CAAC carbene carbon and nitrogen atoms, which is also confirmed by the calculated Mulliken spin densities (C: 0.57, N: 0.21) (Fig. 5b). For 2 the $2 \pi$-aromatic system of the $\mathrm{B}_{2} \mathrm{C}_{2}$ ring is represented by the HOMO$4 \mathrm{a}$, analogous to the HOMO of $2 \pi$-aromatic $\mathrm{C}_{4} \mathrm{H}_{4}{ }^{2+}$ (Fig. 5b). HOMO$8 \mathrm{a}$ also evidences $\pi$-backbonding from the 1,3-diborete ring to the CAAC ligands (Fig. 5b). Frontier molecular orbital plots of $\mathbf{3}$ also display great similarity with those of benzene (Fig. $5 \mathrm{c}$ ) and the parent 1,4-diborabenzene. ${ }^{[26]}$
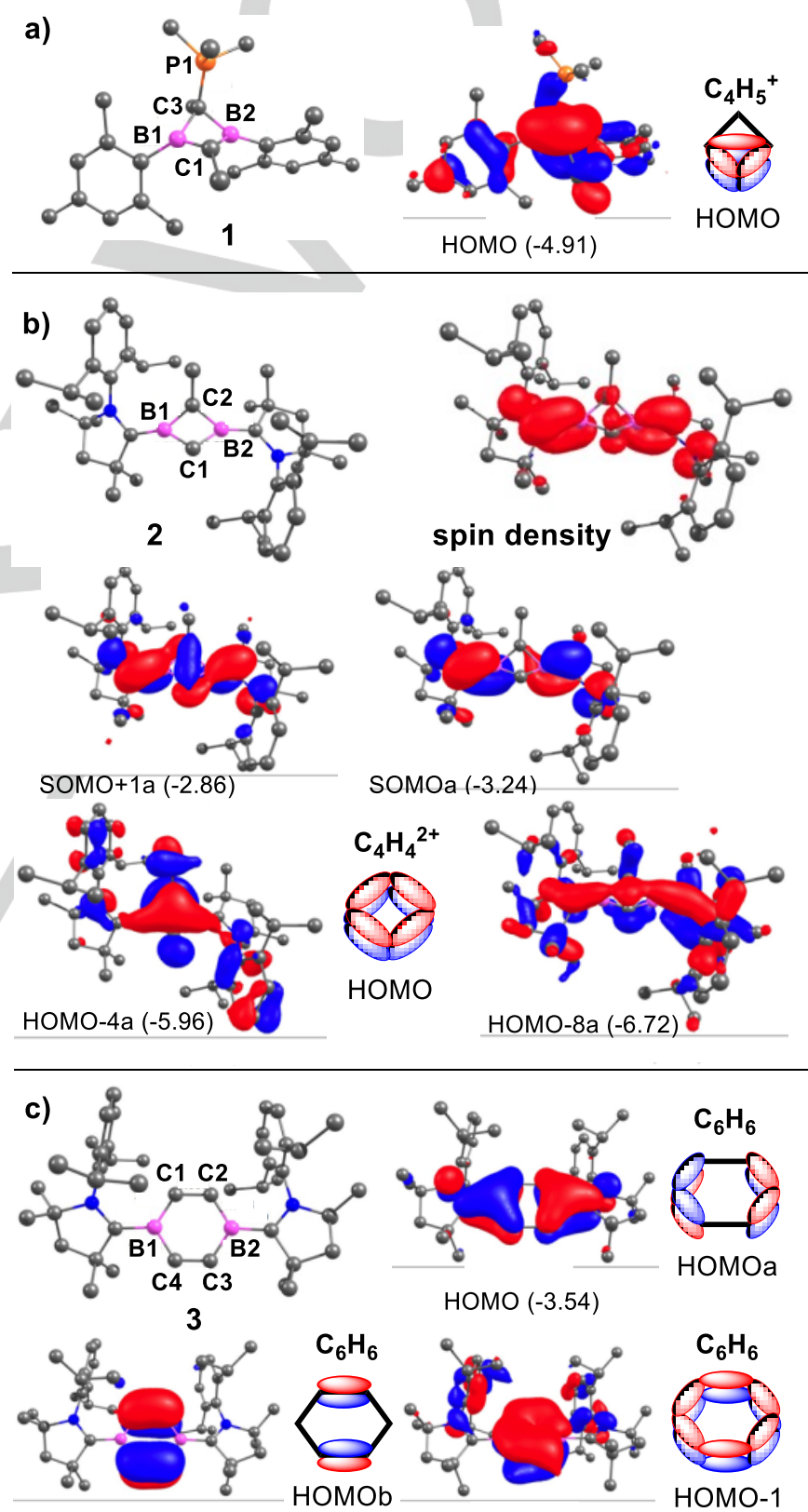

HOMO (-3.54)

HOMO-1 (-4.57)
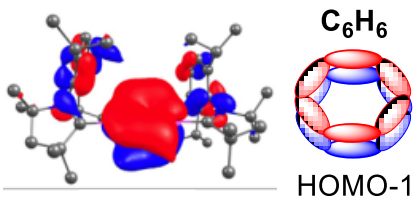

HOMO-7 (-6.10)

Figure 5. Optimized structures and frontier molecular orbitals $(\mathrm{eV})$ of 1-3 at BP86/def2-SVP level, together with schematic representations of the frontier MOs of the analogous aromatic and homoaromatic hydrocarbons. Calculated bond lengths $(\AA)$ : 1 B1-C1 1.503, B2-C1 1.492, B1-C3 1.644, B2-C3 1.673, C3-P1 1.783; 2 B1-C1 1.538, B2-C1 1.530, B1-C2 1.538, B2-C2 1.544; 3 B1-C1/3 1.546, B1-C2/4 1.548, C1-C2 1.396, C3-C4 1.394. 
To assess the aromaticity of the borocarbon ring structures in compounds 1-3 nucleus-independent chemical shift (NICS) calculations were carried out on the structures optimized at B3LYP/def2-TZVPP//def2-SVP level. NICS(0) values for all three compounds were found to be negative $(\mathbf{1}-20.62 ; \mathbf{2}-26.35 ; \mathbf{3}-2.86)$, indicating that compounds $\mathbf{1 - 3}$ all possess a certain degree of aromaticity (Table S1). In order to make reliable comparisons, however, the contributions of orbitals and tensor components to NICS would be required. ${ }^{[30]}$ Due to the open shell nature of compound 2 these contributions cannot be calculated for this particular species, thus precluding any meaningful comparison of the degree of aromaticity between species 1-3 and their hydrocarbon analogues.

In summary we have presented the first examples of uncatalyzed cycloaddition reactions involving unactivated, apolar multiply bonded homodinuclear species of the second period. These reactions provide the first selective route to diborocarbon analogues of the $2 \pi$-aromatic cyclopropenyl cation and cyclobutenyl dication, as well as a novel neutral $6 \pi$-aromatic diborabenzene compound, under ambient conditions. Further experimental work and calculations are currently underway to determine the mechanism of formation and full scope of these compounds, the results of which will be reported in due course. We are continuing to explore cycloaddition reactions of boron-boron multiple bonds with other unsaturated hydrocarbons and polar multiple bonds in order to access an even wider range of valuable boroncontaining heterocycles.

\section{Experimental section}

General experimental details, characterization data for all reported compounds and details of the DFT calculations are all included in the Supporting Information. Crystallographic data have been deposited with the Cambridge Crystallographic Data Centre as supplementary publication nos. 1447233 (1), 1447234 (2) and 1447235 (3) and can be obtained free of charge via www.ccdc.cam.ac.uk/data request/cif.

\section{Acknowledgements}

We acknowledge the Alexander von Humboldt Foundation (Research Fellowship for Postdoctoral Researchers to Dr. M. Arrowsmith). This project has received funding from the European Research Council (ERC) under the European Union Horizon 2020 Research and Innovation Program (grant agreement no. 669054).

Keywords: boron $\bullet$ cycloaddition $\bullet$ multiple bond $\bullet$ aromatic $\bullet$ biradical

[1] E. Hückel, Grundzüge der Theorie ungesättigter und aromatischer Verbindungen, Verlag Chemie, Berlin, 1940.

[2] H.-G. Franck, J. W. Stadelhofer, Industrial Aromatic Chemistry: Raw Materials - Processes - Products, Springer Berlin Heidelberg, 1988.

[3] T. J. Ritchie, S. J. F. Macdonald, R. J. Young, S. D. Pickett, Drug Discovery Today 2011, 16, 164-171.

[4] L. M. Salonen, M. Ellermann, F. Diederich, Angew. Chem. Int. Ed. 2011, 50, 4808-4842.

[5] L. Türker, V. Variş, Polycyclic Aromatic Compounds 2009, 29, 228 266.

[6] G.Maier, J. Meier-Haack, Adv. Polym. Sci. 2008, 216, 1-62.

[7] Reppe, W. Schichting, O. Klager K. Toepel, T. Justus Liebigs Ann. Chem. 560, 1-92 1948.

[8] I. A. Maretina, B. I. Ionin, Regioselective Syntheses of Polysubstituted Benzenes Catalyzed by Transition Metal Complexes in Alkynes in Cycloadditions (Ed. J. C. Tebby,) Wiley-VCH 2014.
[9] M. C. Bertholet, R. Hebd. Séances Acad. Sci. 1866, 62, 905.

[10] a) D. J. De Young, R. West, Chem. Lett. 1986, 883-884; b) S. A. Batcheller, S. Masamune, Tet. Lett. 1988, 29, 3383-3384; c) V. Y. Lee, T. Fukawa, M. Nakamoto, A. Sekiguchi, B. L. Tumanskii, M. Karni, Y. Apeloig, J. Am. Chem. Soc. 2006, $128,11643-11651$.

[11] J. Schneider, J. Henning, J. Edrich, H. Schubert, L. Wesemann, Inorg. Chem. 2015, 54, 6020-6027.

[12] a) R. Kinjo, M. Ichinohe, A. Sekiguchi, N. Takagi, M. Sumimoto, S. Nagase, J. Am. Chem. Soc. 2007, 129, 7766-7767; b) C. Cui, M. M. Olmstead, P. P. Power, J. Am. Chem. Soc. 2004, 126, 5062-5063.

[13] T. Agou, T. Nagata, T. Tokitoh, Angew. Chem. Int. Ed. 2013, 52, 10818-10821.

[14] Z. Zhu, X. Wang, M. M. Olmstead, P. P. Power, Angew. Chem. Int. Ed. 2009, 48, 2027-2030.

[15] B. C. Das, C. Z. Ding, T. Akama, Y. K. Zhang, V. Hernandez, Y. Xia, Future Med. Chem. 2013, 6, 653-676.

[16] L. Weber, L. Böhling, Coord. Chem. Rev. 2015, 284, 236-275.

[17] A. J. V. Marwitz, M. H. Matus, L. N. Zakharov, D. A. Dixon, S.-Y. Liu, Angew. Chem. Int. Ed. 2009, 48, 973-977.

[18] Y. Wang, B. Quillian, P. Wei, C. S. Wannere, Y. Xie, R. B. King, H. F. Schaefer, III, P. v. R. Schleyer, G. H. Robinson, J. Am. Chem. Soc. 2007, 129, 12412-12413.

[19] a) H. Braunschweig, R. D. Dewhurst, K. Hammond, J. Mies, K. Radacki, A. Vargas, Science 2012, 336, 1420-1422; b) J. Böhnke, H. Braunschweig, W. C. Ewing, C. Hörl, T. Kramer, I. Krummenacher, J. Mies, A. Vargas, Angew. Chem. Int. Ed. 2014, 53, 9082-9085.

[20] P. Bissinger, H. Braunschweig, M. A. Celik, C. Claes, R. D. Dewhurst, S. Endres, H. Kelch, T. Kramer, I. Krummenacher, C. Schneider, Chem. Commun. 2015, 51, 15917-15920.

[21] M. L. McKee, Inorg. Chem. 2000, 39, 4206-4210.

[22] M. Menzel, H. J. Winkler, T. Ablelom, D. Steiner, S. Fau, G. Frenking, W. Massa, A. Berndt, Angew. Chem. Int. Ed. Engl. 1995, $34,1340-1343$.

[23] H. Irngartinger, J. Hauck, W. Siebert, M. Hildenbrand, $Z$. Naturforsch. 1991, 46b, 1621-1624.

[24] M. Soleilhavoup, G. Bertrand, Acc. Chem. Res. 2015, 48, 256-266.

[25] P. H. M. Budzelaar, K. Krogh-Jespersen, T. Clark, P. v. R. Schleyer, J. Am. Chem. Soc. 107, 1985, 2113-2119.

[26] J. Singha, Y. Wang, G. Raabe, Z. Naturforsch. 2010, 65a, 113-122.

[27] G. E. Herberich, B. Hessner, Chem. Ber. 1982, 115, 3115-3127.

[28] M.-A. Légaré, G. Bélanger-Chabot, G. De Robillard, A. Languérand, L. Maron, F.-G. Fontaine, Organometallics 2014, 33, 3596-3606.

[29] J. A. K. Howard, I. W. Kerr, P. Woodward, J. Chem. Soc. Dalton Trans. 1975, $2466-2469$.

[30] a) H. Fallah-Bagher-Shaidaei, C. S. Wannere, C. Corminboeuf, R. Puchta, P v. R. Schleyer, Org. Lett. 2006, 8, 863-866. b) Z. Chen, C. S. Wannere, C. Corminboeuf, R. Puchta, P v. R. Schleyer, Chem. Rev. 2005, 105, 3842-3888. 


\section{COMMUNICATION}

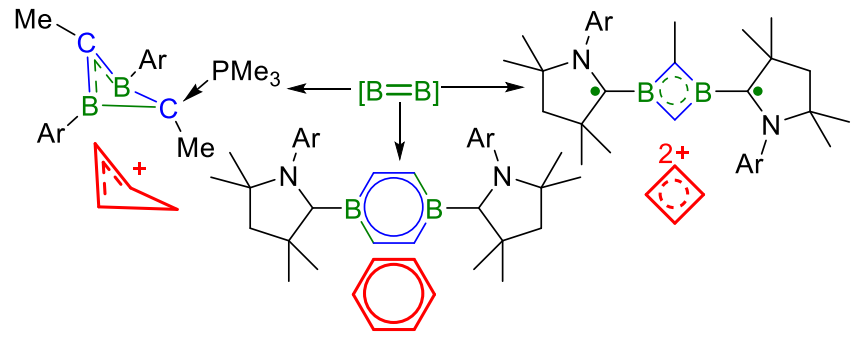

$\mathbf{B}_{2}$-aromatic: Uncatalyzed cycloaddition of apolar alkynes with B-B multiple bonds enables facile and selective access to novel $2 \pi$ - and $6 \pi$ aromatic and $2 \pi$-homoaromatic diboron analogues of $\mathrm{C}_{6} \mathrm{H}_{6}, \mathrm{C}_{4} \mathrm{H}_{4}{ }^{2+}$ and $\mathrm{C}_{4} \mathrm{H}_{5}^{+}$.
Dr. Merle Arrowsmith, Julian Böhnke, Prof. Dr. Holger Braunschweig, * Dr. Mehmet Ali Celik, Christina Claes, Dr. William C. Ewing, Dr. Ivo Krummenacher, Dr. Katharina Lubitz and Christoph Schneider

Page No. - Page No.

Neutral Diboron Analogues of Archetypal Aromatic Species by Spontaneous Cycloaddition 